\title{
Tooth spray with active ingredients casein phosphopeptide - amorphous calcium phosphate (CPP - ACP) and ethanolic extract propolis (EEP) to inhibit tooth demineralization
}

\author{
Muhamad Sahlan a,b*, Lucia Purwanti a,b \\ . ${ }^{a}$ Chemical Engineering Department, Engineering Faculty, University of Indonesia, Kampus Baru UI, Depok, 16424, Indonesia \\ ${ }^{b}$ Bioprocess Engineering, University of Indonesia, Kampus Baru UI, Depok, 16424, Indonesia
}

Article history:

Received: 30 October 2016 / Received in revised form: 26 November 2016 / Accepted: 28 November 2016

\begin{abstract}
Dental caries is a disease caused by the microbial infection that produces localized damage to the tissue classification. The process begins by demineralization in hard tissue followed by damage to the organic material. Dental caries happens because of demineralization without balanced by remineralization. In this study, tooth powder spray and tooth liquid spray was made with active ingredients of $10 \% \mathrm{w} / \mathrm{w} \mathrm{CPP}-\mathrm{ACP}$ (Casein Phosphopeptide - Amorphous Calcium Phosphate) and EEP (Ethanolic Extract Propolis), with the variation of 0\%, 2\%, and 4\% w/w EEP in each preparation to inhibit demineralization. Each preparation should pass organoleptic and viscosity study to maintain the quality. $\mathrm{pH}$ of each preparation was evaluated to ensure that each preparation has $\mathrm{pH}$ above the critical $\mathrm{pH}$ of the oral environment. The stability of polyphenol as the antibacterial agent was evaluated for a month to assure the bioavailability in the preparations. The result shows that each preparation has enough organoleptic aspect and proper viscosity. $\mathrm{pH}$ level in each preparation is stable above critical $\mathrm{pH}$ of mouth environment (5.5), it ranges between 6.5-7.12. Polyphenol content in each preparation is stable with highest poly phenol content in tooth powder spray of $4 \%$ EEP, i.e. $1.39-1.45 \%(\mathrm{w} / \mathrm{w})$. Qualitative evaluation of tooth morphology by SEM shows that preparations can inhibit enamel demineralization relatively to negative control.
\end{abstract}

Keywords: CPP-ACP; EEP; tooth spray; demineralization - remineralization; polyphenol

\section{Introduction}

Periodontal or gum disease is a disease that affects $90 \%$ of Indonesian population, with the highest prevalence is dental caries [1]. Dental caries is a multi-factorial disease that involves the interaction between diet, dental plaque containing bacteria, and host factors, such as tooth surface, saliva, and the acquired pellicle [2]. There was an increase in the prevalence of active caries in Indonesia population compared to the year 2007, i.e. from $43.4 \%$ (2007) to $53.2 \%$ (2013) [1]. It indicates that dental caries is a popular disease in Indonesian society.

Dental caries is initiated via demineralization of tooth mineral by organic acids. Plaque bacteria, following exposure to fermentable carbohydrates, produce the organic acids. When a critical $\mathrm{pH}$ of 5.5 is reached, the organic acids can diffuse into the enamel surface through the acquired pellicle, initiate demineralization. This process continues until equilibrium is reached between the enamel and the oral environment [2].

The natural repair response to demineralization is remineralization, which incorporates minerals from saliva into

\footnotetext{
* Corresponding author.
}

Email:sahlan@che.ui.ac.id the demineralized lesion. The remineralization process of the tooth surface can begin when the oral $\mathrm{pH}$ rises above the acidic level. Calcium and phosphate, which are present in the saliva, diffuse into the enamel with the help of fluoride to remineralize crystalline structures in the demineralized area [3]. The processes of demineralization and remineralization occur several times throughout the day. Dental caries occurs when the balance of demineralization and remineralization is inclined towards demineralization, and the white spot lesion will progress and eventually become a cavity [4].

Research on dental has shown the importance of calcium and phosphate ions in the remineralization process. New study incorporates casein phosphopeptide (CPP) with amorphous calcium phosphate (ACP) to enhance remineralization. Amorphous calcium phosphate (ACP) provides the benefit of having both calcium and phos phate ions close to each other in an amorphous phase. Casein phosphopeptide (CPP), a milk protein, binds to calcium and phosphate, creating complexes of both ions as amorphous calcium phosphate. CPP-ACP can localize calcium and phosphate in dental plaque in the proximity of the tooth, thus making it available when needed. In the presence of an acid environment, such as after eating, when the $\mathrm{pH}$ of the mouth decreases, the casein phosphopeptide proteins release amorphous calcium and phosphate, creating a supersaturated state of calcium and 
phos phate around the tooth [5].

Propolis of ethanolic extract propolis form is added to the tooth spray formula to inhibit bacterial activity, especially $S$. mutants which is responsible for early biofilm formation and decrease in oral environment $\mathrm{pH}$. Propolis also can reduce adhesion of bacteria on the tooth surfaces of the oral cavity and inhibit synthesis of water-insoluble glucan and the action of glucosyltransferase enzymes [6]. Propolis has an antibacterial effect in the presence of the flavonoid and polyphenol. It also enhances the microhardness of enamel surface and has a notable effect on dental hypersensitivity because of its occlusion effect to the tooth morphology [7].

Casein phosphopeptide-amorphous calcium phosphate (CPP - ACP) and ethanolic extract propolis (EEP) are formulized in the form of powder spray and liquid spray. Powder spray has a high adhesion to the tooth surface which can maintain the longer period of active ingredients exposure to the tooth surface. On the other hand, liquid spray can enter teeth sidelines gap that is not easily accessible.

The aims of this research are to evaluate the effect of CPPACP and EEP tooth spray on inhibiting tooth demineralization and to evaluate its $\mathrm{pH}$ stability and polyphenolstability.

\section{Materials and Methods}

Cow pasteurized skimmed milk was obtained commercially from the store around UI Campus, Depok and propolis used was Indonesia ethanolic extract propolis $20 \%$.

\subsection{Sample Preparation}

Pasteurized skimmed milk used as casein source was free fat milk branded "Diamond." Rennet was used to clump the milk branded as Fromase in tablet form, where it was crushed into powder before use. $50 \mathrm{mg}$ rennet was diluted in $10 \mathrm{ml}$ distilled water and stirred at $500 \mathrm{rpm}$ until fully homogenized. Papain enzyme which was used to react with casein has brand "Paya". This has Km: Vmax ratio of 1: 6 which means that 6 $\mathrm{mg}$ of Paya is comparable to $1 \mathrm{mg}$ of pure papain enzyme.

\subsection{Isolation of Casein}

Isolation of Casein from milk is adapted according to Sahlan et al. [8]. A liter of pasteurized skimmed milk was warmed until 35 . $\mathrm{pH}$ was adjusted to 4.6 by the addition of acetic acid. Fifty $\mathrm{mg}$ rennet diluted in $10 \mathrm{ml}$ distilled water was added to the mixture. The mixture was stirred at $200 \mathrm{rpm}$ for 45 minutes. The mixture was incubated at room temperature for 45 minutes and washed with 1 liter of distilled water to inactivate chymosin enzyme. The mixture was incubated until the temperature reached room temperature. Casein was washed with distilled water three times and filtered by micro-filter paper. A gram of casein was dried at $110{ }^{\circ} \mathrm{C}$ and measured every hour for 3 hours or until reaches constant mass to measure casein dry mass.

\subsection{Preparation of CPP - ACP Complex}

Preparation of CPP - ACP complex is adapted from US 2005/003798 patent of Calcium Phosphopeptide Complexes by Reynolds [9]. Casein $10 \%$ w/v or caseinate solution was digested with trypsin at $0.2 \% \mathrm{w} / \mathrm{w}$ of casein. In this study, trypsin from pork was substituted by $2 \% \mathrm{w} / \mathrm{w}$ of papain to fulfill the qualification of a halal product. Casein digested by papain for two $\mathrm{h}$ at $500{ }^{\circ} \mathrm{C}$ with $\mathrm{pH}$ controlled to $8,0 \pm 0,1$ by the addition of $\mathrm{NaOH} 1 \mathrm{M}$. After the digestion, the solution was adjusted to $\mathrm{pH} 4.6$ by $\mathrm{HCl}$ addition. In this study, $\mathrm{HCl}$ was substituted to fulfill the qualification of food grade product. The precipitated sediment was removed by thermoshaker or centrifugation. The supernatant was taken and adjusted to $\mathrm{pH} 9.0$ by adding $\mathrm{NaOH}(1.6 \mathrm{M})$ and $(1 \mathrm{M})$ at which $\mathrm{pH} 9.0$ were added slowly $(\leq 1 \%$ vol per $\min )$ with constant agitation. The $\mathrm{pH}$ held constant at $9.0 \pm 0.1$ by $\mathrm{NaOH}$ addition. $\mathrm{CaCl}_{2}$ and sodium phos phate were added to the final concentrations of $100 \mathrm{mM}$ and $60 \mathrm{mM}$ respectively. CPPACP was microfiltered to enhance the concentration.

\subsection{Formulation of Tooth Powder Spray and Tooth Liquid Spray}

This study is to evaluate the effect and the stability of CPP-ACP which is formulated with EEP in powder spray and liquid spray form. CPP used in the formulation is $10 \%$ by weight, while EEP was added in 3 variants, $0 \%, 2 \%$ and $4 \%$. Excipients employed in the preparations are sodium carboxymethylcellulose, glycerin, propylene glycol, Tween 80 and distilled water.

The organoleptic study was measured qualitatively through appearance and the texture of tooth coating gel. $\mathrm{pH}$ stability was evaluated for four weeks to make sure the $\mathrm{pH}$ of the tooth spray is above critical pH (5.5). It is indispensable because tooth gel will be smeared to enamel. Polyphenol stability in the formulation was evaluated for four weeks through visible spectrophotometer. Efficacy of CPP - ACP and EEP tooth spray for inhibiting tooth demineralization was assessed by Scanning Electron Microscope (SEM). This method is adapted from [10]. Eight samples of maxillary premolar teeth that showed no evidence of white spot lesion, enamel cracks, or carries on visual inspection were taken for evaluation. All samples were cut by diamond disc burr on the cement-enamel junction, leaving the teeth roots, in size $3 \mathrm{~mm} \times 5 \mathrm{~mm}$ then coated by the acid resistant resin. Each sample except positive control was then immersed into 5\% phosphoric acid demineralizing solution for 5 hours as the simulation of demineralization of teeth. Six samples (exception of positive and negative control) were rubbed with tooth spray for $3 \mathrm{~min}$ using micro applicator, followed by washing with deionized water. Every single application of tooth spray was followed by washing with deionized water. Tooth gel application was made 30 times as the simulation of 30 times of tooth spray usage. All samples were immersed in artificial saliva containing $20 \mathrm{mmol} / \mathrm{L} \mathrm{NaHCO}_{3}, 3 \mathrm{mmol} / \mathrm{L} \mathrm{NaH} \mathrm{NO}_{4}$ and 1 $\mathrm{mmol} / \mathrm{L} \mathrm{CaCl} 2$ for 24 hours then washed by deionized water. Morphology of all teeth samples were then evaluated by SEM.

\section{Results and Discussion}

\subsection{Organoleptic Study}

Organoleptic study was conducted by evaluating color, 
viscosity, sedimentation rate and homogeneity of samples. Powder spray has powder appearance which the color gets darker by the higher addition of propolis. Each sample can change into the gel after dropped by water. This property is needed to maintain the adhesion of tooth spray to the teeth. The liquid spray has the slightly viscous appearance and the color gets darker by the higher addition of propolis. Sediment was formed after 8 minutes. However, it can change to homogenous solution again after light shaking. The liquid spray has the viscosity higher than saliva, so it will not easy to be washed out by saliva, this property can maintain higher contact of active ingredients to the teeth. Organoleptic result summary is shown in Table 1 and Table 2.

Table 1. Organoleptic study of powder spray

\begin{tabular}{lll}
\hline \multicolumn{1}{c}{ Sample } & \multicolumn{1}{c}{ Texture } & \multicolumn{1}{c}{ Color } \\
\hline $10 \%$ CPP-ACP & $\begin{array}{l}\text { Slightly coarse powder, } \\
\text { homogenous }\end{array}$ & Compact white \\
& Fine powder, homogenous & Pale brown \\
and $2 \%$ EEP & & \\
$10 \% \mathrm{CPP}-\mathrm{ACP}$ & Fine powder, homogenous & Pale brown, darker \\
and $4 \% \mathrm{EEP}$ & & than sample2 \\
\hline
\end{tabular}

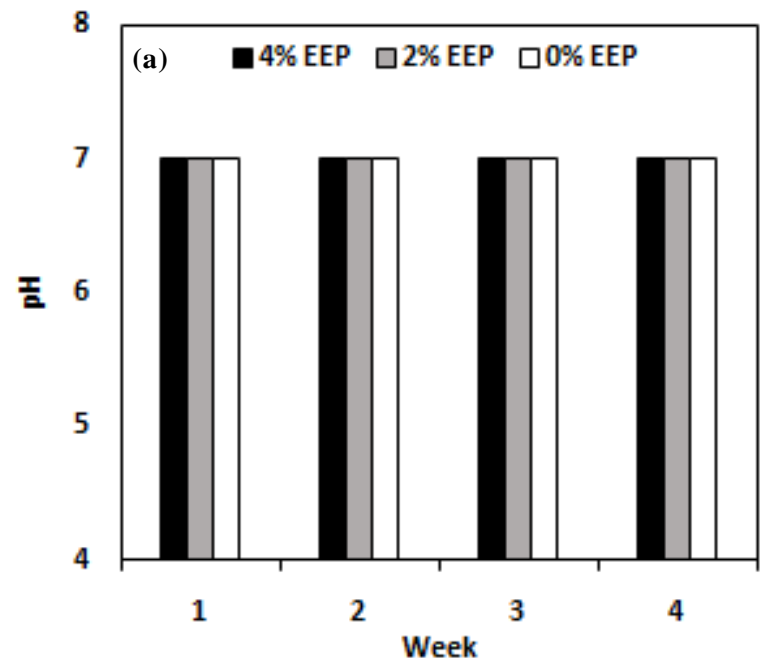

Table 2. Organoleptic st udy of liquid spray

\begin{tabular}{lll}
\hline \multicolumn{1}{c}{ Sample } & \multicolumn{1}{c}{ Texture } & \multicolumn{1}{c}{ Color } \\
\hline $10 \%$ CPP-ACP & $\begin{array}{l}\text { Slightly viscous, } \\
\text { homogenous } \\
10 \% \text { CPP-ACP }\end{array}$ & $\begin{array}{l}\text { Semi-transparent } \\
\text { white }\end{array}$ \\
and $2 \%$ EEP & homogenous & Brown \\
$10 \%$ CPP-ACP & Slightly viscous, & Brown, darker than \\
and 4\% EEP & homogenous & sample 2 \\
\hline
\end{tabular}

\section{2. $p H$ Stability}

$\mathrm{pH}$ stability was evaluated for four weeks. It shows that each preparation has stable $\mathrm{pH}$ evaluated for four weeks. $\mathrm{pH}$ of powder spray was constant at $\mathrm{pH} 7.0$, while ph level of liquid spray fluctuated from $6.5-7.12$. However, the degree of acidity of each preparation was above the critical $\mathrm{pH}$, i.e. 5.5 , so it will not solubilize the tooth mineral. Also, plaque or biofilm caused by the bacterial activity will not be formed. Stable $\mathrm{pH}$ shows that no reaction or no contamination of the preparations occurred.

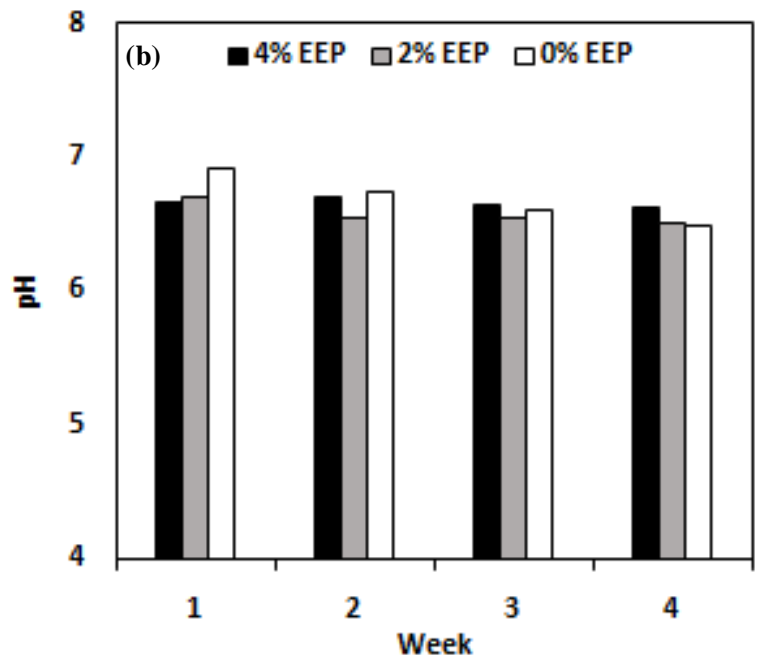

Fig. 1. pH dynamics of: (a) powder spray and (b) liquid spray

\subsection{Polyphenol Stability}

Polyphenol has existed only on tooth spray containing ethanolic extract propolis. Polyphenol stability was evaluated for four weeks and all samples containing propolis showed a relatively stable polyphenol content. Polyphenol content in $10 \% \mathrm{CPP}-\mathrm{ACP}-2 \% \mathrm{EEP}$ and $10 \% \mathrm{CPP}-\mathrm{ACP}-4 \% \mathrm{EEP}$ liquid form were varied between $0.21-0.29 \%$ and $0.33 \%$ $0.53 \%$ by weight respectively, whereas polyphenol content in $10 \% \mathrm{CPP}-\mathrm{ACP}-2 \% \mathrm{EEP}$ and $10 \% \mathrm{CPP}-\mathrm{ACP}-4 \% \mathrm{EEP}$ powder form were varied between $0.68 \%-0.73 \%$ and $1.39 \%$ $1.45 \%$ by weight sequentially. Polyphenols contained in a powder form was higher than polyphenols contained in a liquid form. It happened because powder spray is a concentrated form. Fig. 2 shows polyphenol stability graphs for four weeks.

Polyphenol on propolis has antibacterial activity on S. mutants with minimum inhibitory concentration (MIC) 14 -
$28(0.014-0.028 \% \quad \mathrm{w} / \mathrm{w})$ and minimum bactericidal concentration (MBC) $58-112(0.058-0.112 \%$ w/w) [11]. A polyphenol contained in the tooth spray is higher than MBC and MIC so that it can inhibit S. Mutans growth. It is also proven on the earlier study by Sulistyani [12]. In this study, CPP - ACP combined by $2 \%$ EEP and $4 \%$ EEP tooth coating gel could inhibit $37.75 \%$ and $57.73 \%$ S. Mutans growth relative to negative control respectively.

\subsection{Tooth Remineralization}

SEM was used to determine the morphological variations between the treated surface and untreated surface. SEM evaluation can be seen in Figs. 3-6. Control negative micrographs show many demineralizations occur on the tooth surface which is marked by prism cores and enamel rods exposition. All experimental gropus applied by tooth sprays show a thorough remineralization compared to negative 
control, with the best result is tooth sample implemented by $10 \%$ CPP-ACP - 4\% EEP powder spray and liquid spray. Tooth surface looks smooth and has consistent patterns; remineralization happens to the entire surface evenly.

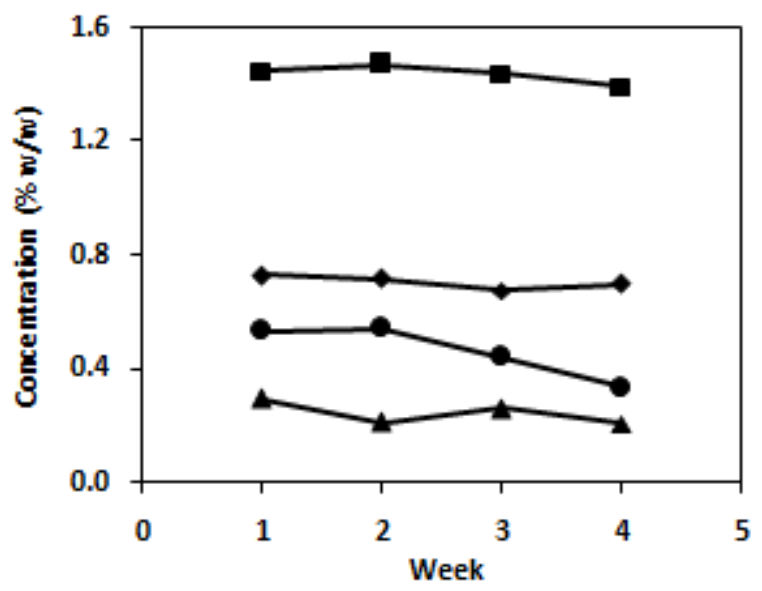

Fig. 2. Comparison of polyphenol stability in different preparation: 10\% CPP ACP-2\% EEP powder (closed diamonds); 10\% CPP ACP-4\% EEP powder (closed squares); 10\% CPP ACP-2\% EEP liquid (closed triangles); 10\% CPP ACP-4\% EEP liquid (closed circles)

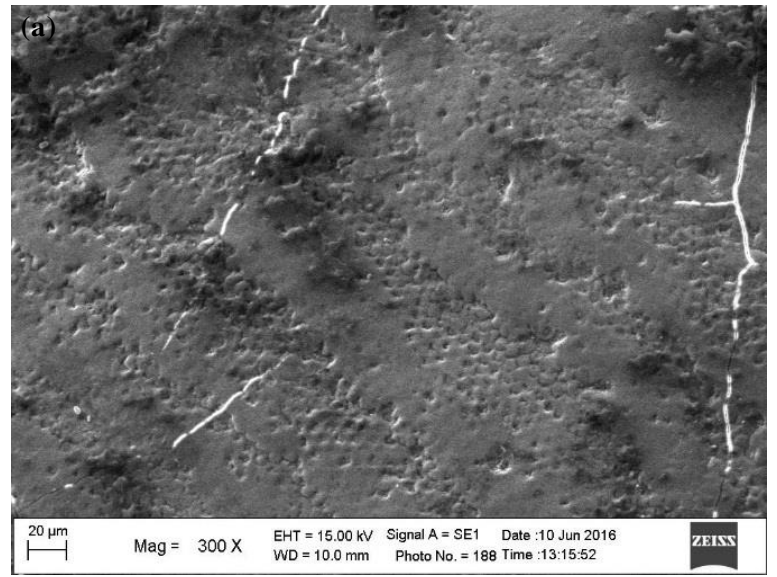

When CPP - ACP is applied to the teeth, casein is opeptides will stick to the teeth, delivering calcium ions and phosphate ions to where it is needed. Calcium and phosphate ions came into the enamel rod towards the area intratubular and formed apatite crystals. With this process, enamel remineralization occurs. Lost minerals replaced by new calcium and phosphate ions provided by CPP-ACP. Localization of ACP on the tooth surface buffers the free calcium and phosphates ions, helping to maintain supersaturation state which respects to inhibiting demineralization and enhancing remineralization.

Teeth treated with CPP-ACP and EEP tooth spray show smoother surface compared to CPP-ACP application only. It happens because propolis adheres well to the tooth surface and helps to maintain ACP adhesion to the tooth surface. Propolis also has an occlusive effect (pore clogging) which can reduce exposed pore of dentin [7].

\section{Conclusion}

The $\mathrm{pH}$ level in each preparation is stable above critical $\mathrm{pH}$ of mouth environment (5.5), it ranges between 6.5 - 7.12. Polyphenol content in each preparation is stable with the highest polyphenol content is in tooth powder spray

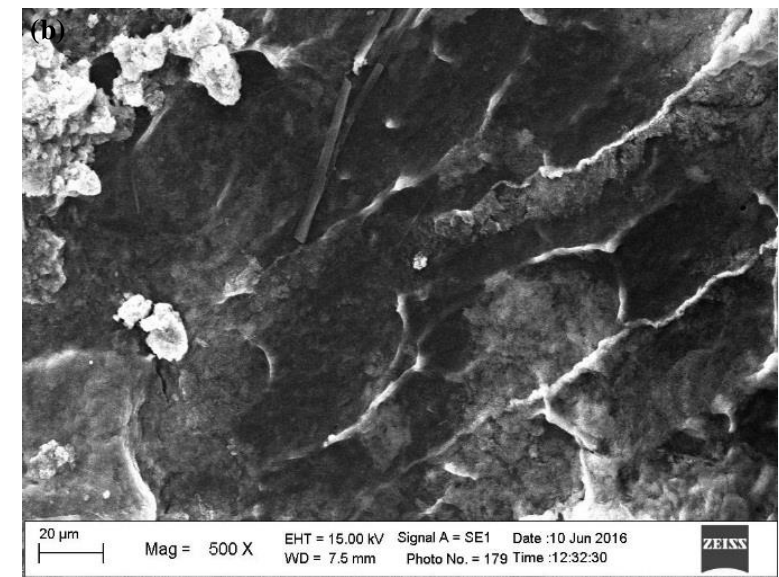

Fig 3. Micrograph for (a) positive control and (b) negative control
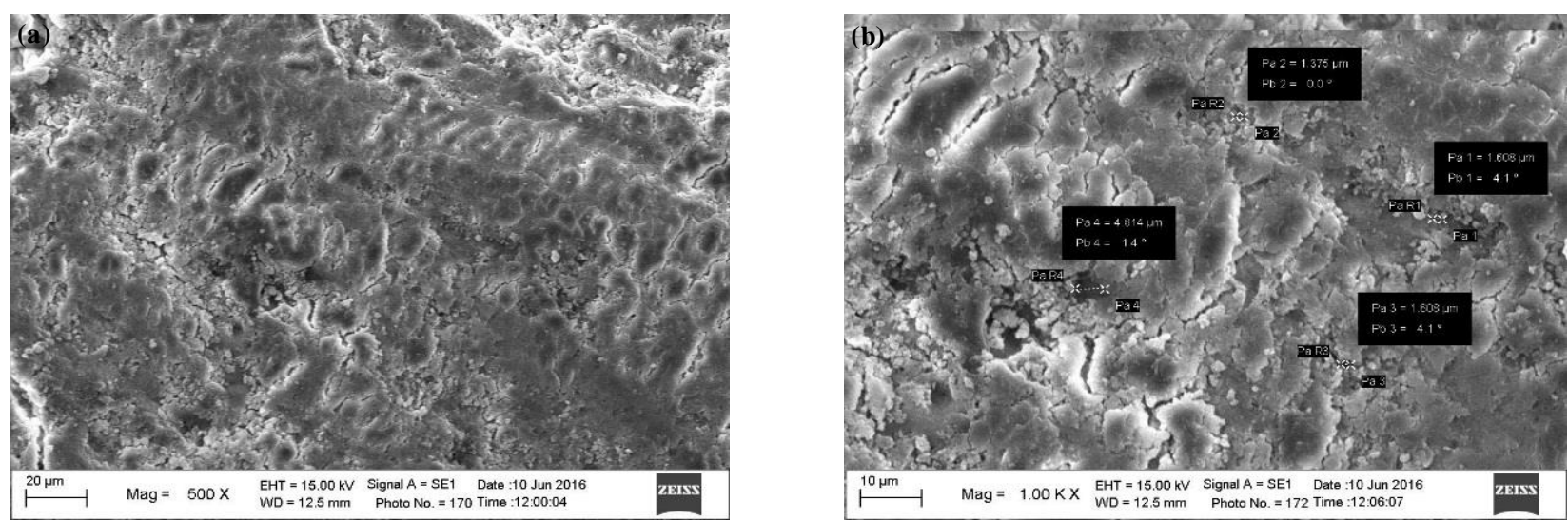

Fig. 4. Micrograph for 10\% CPP-ACP + 0\% EEP of: (a) liquid spray and (b) powder spray

with $4 \%$ EEP, i.e. $1.39-1.45 \%(w / w)$. The CPP-ACP and EEP powder and liquid tooth spray were effective in preventing demineralization of the enamel. However, $10 \%$
CPP-ACP combined with $4 \%$ EEP in the formed liquid and powder sprays show through remineralization more efficiently. Further studies are needed to determine the 
mineral gain required for remineralization and tooth spray

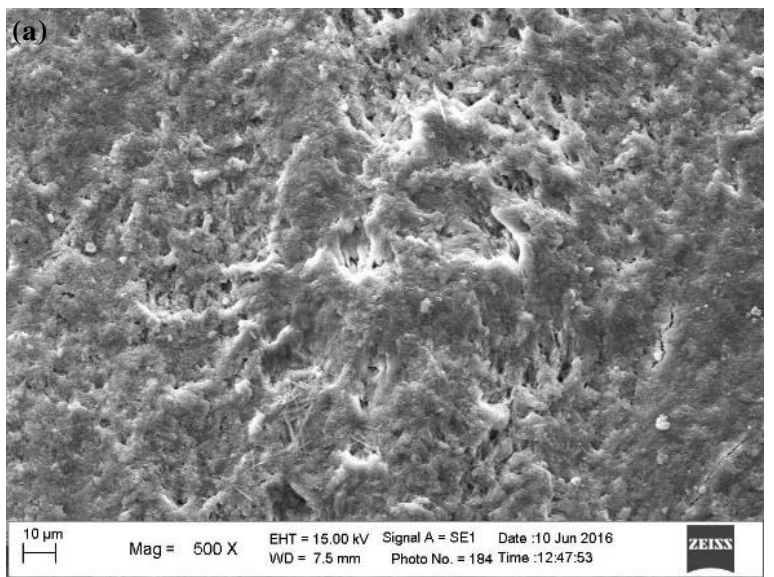

effects on teeth under in vivo conditions .

Fig 5. Micrograph for 10\% CPP-ACP + 2\% EEP of: (a) liquid spray and (b) powder spray
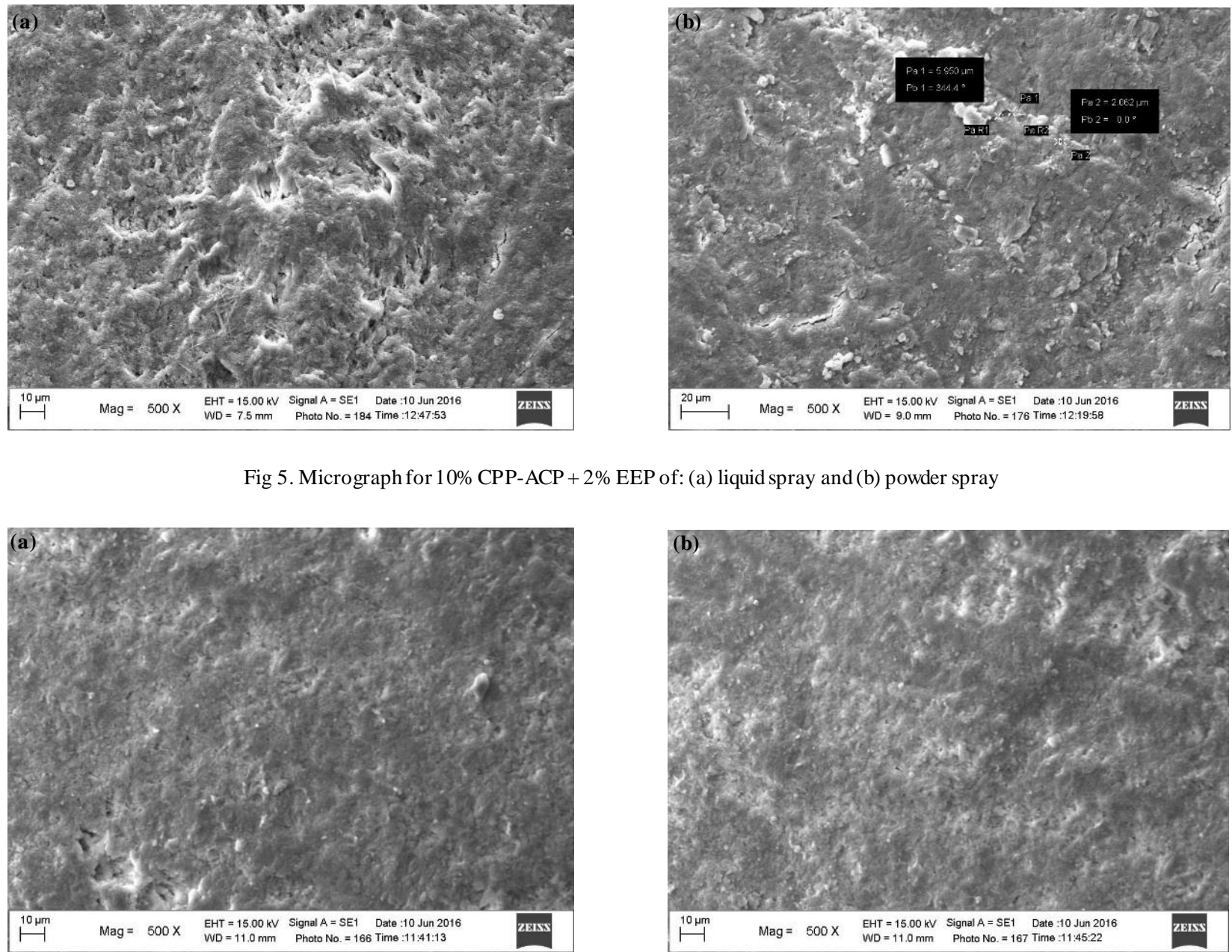

Fig 6. Micrograph for 10\% CPP-ACP + 4\% EEP of: (a) liquid spray and (b) powder spray

\section{ACKNOWLEDGMENT}

This research was supported by Student Creativity Program funding from Ministry of Research, Technology and Higher Education, Indonesia.

\section{REFERENCES}

1. Ministry of Health, Indonesia at Central Data and Information: Masalah Gigi dan Mulut. Jakarta: Kementerian Kesehatan RI, (2014).

2. Clark, Kristin Dumboski. The Efficacy of 37\% Phosphoric Acid + Mi Paste Plus on Remineralization of Enamel White Spot Lesions. Io wa : University of Iowa (2011).

3. Cury, J.A. and Tenuta, L.M. Enamel Remineralization: Controlling The Caries Disease or Treating Early Caries Lessions? (2009), Braz Or al Res, pp. 23-30.

4. Featherstone, J.D.B. Dental Caries : A Dynamic Disease Process. (2008), Australia Dental Journal, pp. 286-291.

5. Pulido, MT, et al. The Inhibitory Effect of MI Paste, Fluoride and Combination of Both on The Progression of Artificial Caries - Like Lesions in Enamel. (2008), Operative Dentistry Journal 33(5), pp. 550 555 .

6. Sabir, Ardo. Aktivitas antibakteri flavonoid propolis Trigona sp terhadap bakteri Streptococcus mut ans (in vitro). Majalah Kedo kte ran Gigi. 38(3)(2005),pp.135-141.

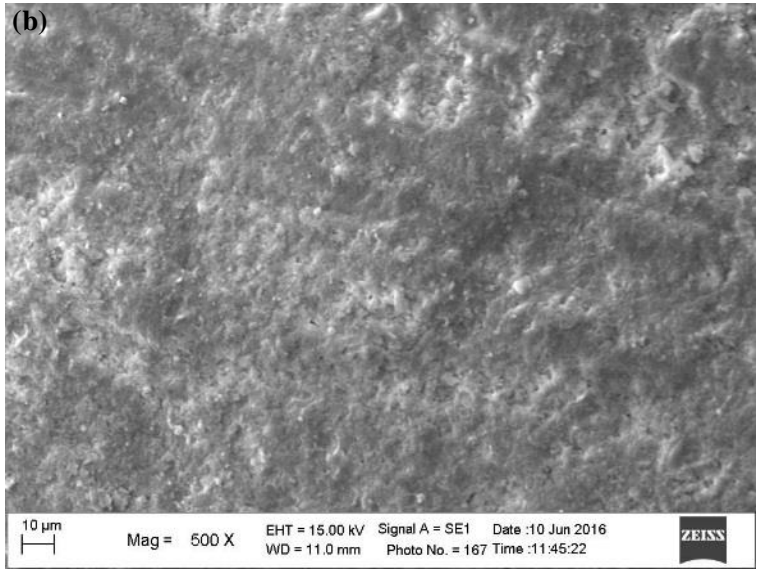

7. Hongal, Sudhir, et al. The Effect of $30 \%$ Ethanolic Extract of Indian Propolis on Replica of Human Dentin Compared Against Commmercially Available Desentizing Agent : A Methodological SEM Study In Vitro. (2014), Pharmacognosy Res Apr - Jun 6(2), p p. 113 119.

8. Sahlan, Muhamad and Pramadewi, Indrianti. Nanoencapsulation of The Flavaonoids Isolated from Phaleria macrocarpa Leaf by Casein Micelle. (2012), Int J Bio Sci July 3(3), pp. 472 - 478.

9. Reynold, Eric. Casein Phosphopeptide - Amorphous Calcium Phosphate Nano Complexes. Unites States patent O037948,(2005).

10. Jayarajan, J., et al. Efficacy of CPP-ACP and CPP-ACPF on Enamel Remineralization - An In Vitro Study Using Scanning Electron Microscope and DIAGNOdent. (2011), Indian J Dent Res, pp. 77 - 82.

11. Liberio, Silvana A., et al. The Potential Use of Propolis as Cariostatic Agent and Its Actions on Mutans Group Streptococci. (2009), Journal of Ethnopharmacology,pp. 1-9.

12. Sulistyani, Nindya. Pembuatan Tooth Gel yang Mengandung Ca sein Phosphopeptide - Amorphous Calcium Phosphatedan Propolis un tuk Menghambat Demineralisasi. (2016) University of Indonesia. Bachelo r Thesis.

13. Selwitz, Robert H, Ismail, Amid I and Pitts, Nigel B. Dental Caries. (2007), Lancet, pp. 51-59.

14. Farooq, Imran, et al. A Review of Novel Dental Caries Preventive Material: Casein Phosphopeptide-Amorphous Calcium Phosphate (CPP-ACP) Complex. (2013), King Saud University Journal of Den tal Sciences, pp. 47-51. 